\title{
Ignition characteristics of dual-fuel methane-n-hexane-oxygen-diluent mixtures in a rapid compression machine and a shock tube
}

\author{
Yizhuo He ${ }^{\mathrm{a}, \mathrm{b}}$, Yingdi Wanga,b, Claire Grégoire ${ }^{\mathrm{c}}$, Urszula Niedzielska ${ }^{\mathrm{c}, \mathrm{d}}$, Remy \\ Mével $^{\mathrm{a}, \mathrm{b}, *}$, Joseph E. Shepherde,* \\ ${ }^{a}$ Center for Combustion Energy, Tsinghua University, Beijing, China. \\ ${ }^{b}$ Department of Automotive Engineering, Tsinghua University, Beijing, China. \\ ${ }^{c}$ Graduate Aeronautical Laboratories, California Institute of Technology, Pasadena, USA \\ ${ }^{d}$ Warsaw University of Technology, Warsaw, Poland
}

\begin{abstract}
Ignition delay times of methane-n-hexane-oxygen mixtures were studied experimentally and numerically in a wide temperature range $(640-2335 \mathrm{~K})$ using both a rapid compression machine (RCM) and a shock tube (ST). The RCM results demonstrated a two-stage ignition and negative temperature coefficient (NTC) behavior. Increasing n-hexane concentration, pressure and equivalence ratio shortened the ignition delay time. For the ST experiments, the addition of $10 \%$ n-hexane (relative to methane) can reduce the ignition delay time dramatically. However, no further reduction effect can be achieved with increasing addition of n-hexane from $10 \%$ to $20 \%$. In addition, increasing equivalence ratio reduces the effect of n-hexane addition on ignition delay time. Three detailed chemical mechanisms, CaltechMech, GalwayMech and LLNLMech, were evaluated based on a quantitative error analysis. LLNLMech and CaltechMech demonstrated the best performance in the RCM and ST temperature ranges, respectively. Chemical kinetic analyses showed that the addition of n-hexane to methane provides some chemical pathways not available for methane oxidation which result in the production of active radicals and eventually accelerate the ignition of the methane-oxygen mixtures. The crucial intermediate species for the ignition process are $\mathrm{H}_{2} \mathrm{O}_{2}$ and $\mathrm{H}$ under RCM and ST conditions, respectively.
\end{abstract}

${ }^{*}$ Corresponding author: mevel@mail.tsinghua.edu.cn 
Keywords: Dual-fuel ignition, Methane-n-hexane mixtures, Rapid compression machine, Shock tube, Chemical kinetics modeling

\section{Introduction}

A shortage of crude oil is expected within this century. In addition, air pollution is becoming more concerning and more stringent regulations on pollutant emissions from internal combustion engines are anticipated. The use of natural gas as a fuel for internal combustion engine (ICE) operating under diesel conditions is a promising approach for addressing these issues $[1,2]$.

Advantages of natural gas include vast and geographically widespread resources, as well as some relevant combustion parameters such as a high octane number, a high anti-knock capability and low pollutant emissions, leading to a substantial reduction in carbon dioxide emissions, and possibly of NOx and particulate matter as compared to diesel and gasoline fueled IC engines [3, 4, 5, 6]. On the other hand, natural gas has unfavorable combustion characteristics, such as a long ignition delay time, high auto-ignition temperature, low flame propagation speed for lean mixtures and poor lean burn capability. These can result in increased cycle-to-cycle variations, reduced thermal efficiency, and increased HC emission under fuel-lean conditions $[7,8,9]$. Consequently, a strategy to enhance ignition is needed to take advantage of the low emission of soot and NOx and the reduced formation of unburnt $\mathrm{HC}$ and CO possible with natural gas fueled IC engines. Pilot-ignited dual-fuel engines have proven to be a promising engine concept to improve and control the ignition of natural gas-air mixture under diesel conditions [2]. This strategy consists of triggering the ignition of a premixed charge using a micro-spray of diesel fuel $[10,11,12,13]$.

Properly optimized, the adoption of the pilot injection strategy would reduce the delay to the main ignition event, smoothen the premixed combustion phase, as well 
as reduce noise and pollutant emissions at partial loads [14, 15, 16, 17]. However, because of the complexity of spray-induced ignition, substantial efforts are needed to optimize the combustion chamber geometry, the spray characteristics and the ignition strategies $[18,19,20,21,22,14,23,24]$. In order to reducing the dependence on engine tests and to improving work efficiency, such an optimization process could be performed using Computational Fluid Dynamics (CFD) simulations, coupling the fluid mechanics and the appropriate chemical kinetic mechanism. It has been reported that the delay to ignition, the location of the ignition of the diesel spray, as well as the energy release rate characteristics are very sensitive to the content of methane in the methane-air pre-mixture $[25,4,26,18]$. This indicates that the ignition process is very sensitive to the mixing process and to the chemical kinetics. Consequently, reliable chemical kinetic mechanisms are needed to support CFD simulations to optimizing this type of pilot-ignited dual-fuel engine. Regarding development and validation of chemical kinetic mechanisms, ignition delay time is widely considered as a combustion characteristic parameter of primary importance.

Given the complexity and variability of both natural gas and diesel composition, simple surrogate fuels should be employed to perform related chemical kinetic investigations. For natural gas, methane is generally considered as an appropriate surrogate. For diesel, a large number of surrogates have been proposed and may include up to 10 hydrocarbons [27]. The present study was carried out with nhexane because it can be studied with room temperature starting conditions. While numerous experimental data on ignition are available for methane- $[28,29,30]$ and nhexane-based [31, 32, 33, 34, 35] mixtures, experimental data for dual-fuel methanen-alkane mixtures are scarce. Liang et al. [36] studied the ignition delay-time of n-heptane-methane-based mixtures in a shock tube. The present study differs from that of Liang et al. in the approach used to prepare the mixtures. To determine the respective effects of methane and n-heptane, they replaced a fraction of methane by n-heptane whereas we have chosen to add a certain quantity of n-hexane to methane-oxygen-diluent mixtures of a given equivalence ratio. The present study also significantly extends the range of temperatures and pressures over which the 
ignition of the dual-fuel mixtures is studied.

The objective of the present study was to investigate experimentally and numerically the impact of n-hexane addition on the ignition of methane. Due to its higher vapor pressure as compared to n-heptane, n-hexane was chosen as a diesel surrogate. We recognize that some of the physical properties of diesel are not captured when using a single alkane such as n-hexane since real diesel is a blend of hundred of hydrocarbons with carbon numbers in the range $\mathrm{C}_{10}-\mathrm{C}_{24}$, and a boiling temperature in the range $190-360{ }^{\circ} \mathrm{C}$ [37]. Studying real diesel requires to solve a number of technical difficulties including heating the experimental facilities and ensuring the thermal stability of the hydrocarbon-air mixtures [38]. A rapid compression machine (RCM) and a shock tube (ST) were employed to assess the ignition characteristics of dual-fuel methane-n-hexane-oxygen-diluent mixtures in a wide range of temperature and pressure. In addition, three detailed chemical kinetic mechanisms were evaluated. Chemical kinetic analyses were conducted to unravel the underlying ignition mechanism of methane-n-hexane mixtures.

\section{Material and method}

\subsection{Rapid compression machine}

The low- and intermediate-temperature (640-878 K) ignition experiments were performed using the Tsinghua University Rapid Compression Machine facility which detailed description is given in Di et al. [39].

The ignition delay time was defined as the time between the end of compression and the maximum pressure derivative. For two-stage ignition, the first-stage ignition was defined as the time between the end of compression and the first local maximum in the pressure derivative curve. The uncertainty on the delay time is estimated to be approximately 10-15\%. A typical experimental pressure signal obtained during the RCM experiments is shown in Figure 1 (a). 


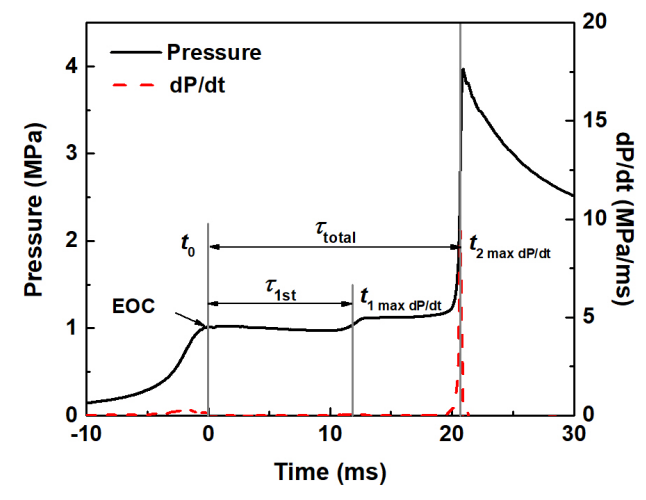

(a) RCM pressure signal

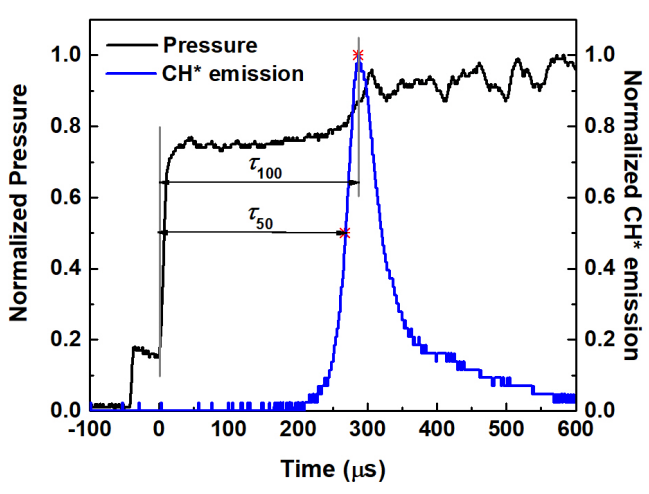

(b) ST pressure and $\mathrm{CH}^{*}$ signals

Figure 1: Typical experimental signals obtained using the RCM and ST facilities. (a): Mixture 1; $\mathrm{P}=2 \mathrm{MPa} ; \mathrm{T}=670 \mathrm{~K}$. (b) Mixture 14; $\mathrm{P}=415 \mathrm{kPa} ; \mathrm{T}=1353 \mathrm{~K}$. EOC stands for end of compression

\subsection{Shock tube}

The high-temperature (1250-2335 K) ignition experiments were carried out using the Galcit 6-inch Shock Tube. A detailed description of the ST apparatus and diagnostics was previously given in $[40,41,42]$. The ignition event was studied behind reflected shock waves using $\mathrm{OH}^{*}, \mathrm{CH}^{*}$, and $\mathrm{CO}_{2}{ }^{*}$ emission. It was characterized using two times of reaction defined as: (i) the time to half emission maximum $\left(\tau_{50 \%}\right)$; and (ii) the time to the emission maximum $\left(\tau_{100 \%}\right)$. The uncertainty on the characteristic reaction times is estimated to be approximately 20\%. Typical pressure and $\mathrm{CH}^{*}$ emission signals obtained during the ST experiments are shown in Figure 1 (b).

\subsection{Test mixtures}

The reactive mixtures were prepared in a separate tank using the partial pressure method for both the RCM and the ST experiments. The tank of the RCM allowed mixtures to mix through diffusion for several hours before performing the experiments. A brushless fan was mounted inside the tank for the ST experiments, hence, approximately one or two hours were needed to ensure homogeneity. The residual pressure in both mixture tanks before mixture preparation was below $1 \mathrm{~Pa}$. Ultra-high purity grade methane (99.999\%), oxygen (99.999\%), nitrogen (99.999\%), argon $(99.999 \%)$ and pure n-hexane $(99 \%)$ were used for all the experiments. No 
further purification was performed. The equivalence ratio was defined based on both the main fuel $\left(\phi_{m}\right)$ only and on the total amount of fuel $\left(\phi_{t}\right) . \phi_{m}$ is expressed as

$$
\phi_{m}=\frac{X_{F_{M}} / X_{O_{2}}}{\left(X_{F_{M}} / X_{O_{2}}\right)_{\text {stoic }}},
$$

whereas $\phi_{t}$ is expressed as

$$
\phi_{t}=\frac{2 X_{C}+0.5 X_{H}}{X_{O}} .
$$

The addition ratio of the additive fuel was defined as

$$
R_{A}=\frac{X_{F_{A}}}{X_{F_{M}}},
$$

where $X_{F_{M}}$ and $X_{F_{A}}$ denote the amount of main fuel and additive fuel, respectively. $F_{M}$ stands for methane and $F_{A}$ stands for n-hexane except for Mixtures 14 to 16 for which n-hexane was the main fuel and methane was the added fuel. For RCM experiments, both nitrogen and argon were employed as diluent gas in order to extend the range of tested temperatures by altering the overall heat capacity. For the ST experiments, argon was used as the diluent gas to minimize the effect of vibrational relaxation and reflected shock wave bifurcation. The dilution ratio was selected to ensure the measured ignition delay times are in the appropriate ranges of observation times of the present RCM and ST facilities. Detailed mixture compositions and experimental conditions are summarized in Table 1. 
Table 1: Experimental conditions and mixture compositions employed in the present work.

\begin{tabular}{|c|c|c|c|c|c|c|c|c|c|c|}
\hline \multirow{2}{*}{ Mixture } & \multicolumn{5}{|c|}{ Mole Fraction (\%) } & \multirow{2}{*}{$\phi_{m}$} & \multirow{2}{*}{$\phi_{t}$} & \multirow{2}{*}{$T(\mathrm{~K})$} & \multirow{2}{*}{$P(\mathrm{kPa})$} & \multirow{2}{*}{ Facility } \\
\hline & $\mathrm{n}-\mathrm{C}_{6} \mathrm{H}_{14}$ & $\mathrm{CH}_{4}$ & $\mathrm{O}_{2}$ & $\mathrm{~N}_{2}$ & $\mathrm{Ar}$ & & & & & \\
\hline 1 & 0.94 & 9.42 & 18.87 & 23.58 & 47.19 & 1.00 & 1.47 & $652-853$ & 1000,2000 & $\mathrm{RCM}$ \\
\hline 2 & 1.88 & 9.4 & 18.9 & 13.22 & 56.6 & 1.00 & 1.94 & $640-825$ & 1000,2000 & $\mathrm{RCM}$ \\
\hline 3 & 0.49 & 4.92 & 19.72 & 30.57 & 44.3 & 0.50 & 0.74 & $656-878$ & 1000,2000 & $\mathrm{RCM}$ \\
\hline 4 & - & 1 & 3 & - & 96 & 0.67 & 0.67 & $1630-2125$ & $234-315$ & $\mathrm{ST}$ \\
\hline 5 & - & 1.33 & 2.67 & - & 96 & 1.00 & 1.00 & $1539-2335$ & $233-297$ & $\mathrm{ST}$ \\
\hline 6 & - & 2 & 2 & - & 96 & 2.00 & 2.00 & $1666-2286$ & $200-295$ & $\mathrm{ST}$ \\
\hline 7 & 0.1 & 1 & 3 & - & 95.9 & 0.67 & 0.98 & $1398-1723$ & $306-386$ & ST \\
\hline 8 & 0.13 & 1.33 & 2.66 & - & 95.88 & 1.00 & 1.46 & $1510-1761$ & 278-332 & $\mathrm{ST}$ \\
\hline 9 & 0.2 & 2 & 2 & - & 95.8 & 2.00 & 2.95 & $1675-2156$ & 219-294 & $\mathrm{ST}$ \\
\hline 10 & 0.2 & 1.1 & 2.99 & - & 95.71 & 0.74 & 1.37 & $1455-1784$ & $271-380$ & $\mathrm{ST}$ \\
\hline 11 & 0.26 & - & 3.74 & - & 96 & 0.66 & 0.66 & $1298-1474$ & $320-377$ & $\mathrm{ST}$ \\
\hline 12 & 0.38 & - & 3.62 & - & 96 & 1.00 & 1.00 & $1298-1585$ & $258-405$ & $\mathrm{ST}$ \\
\hline 13 & 0.7 & - & 3.3 & - & 96 & 2.02 & 2.02 & $1336-1606$ & 308-392 & $\mathrm{ST}$ \\
\hline 14 & 0.26 & 0.03 & 3.69 & - & 96.02 & 0.67 & 0.69 & $1247-1536$ & $353-417$ & ST \\
\hline 15 & 0.38 & 0.04 & 3.62 & - & 95.96 & 1.00 & 1.02 & $1297-1479$ & 340-402 & ST \\
\hline 16 & 0.7 & 0.07 & 3.3 & - & 95.93 & 2.02 & 2.06 & $1368-1490$ & $324-365$ & $\mathrm{ST}$ \\
\hline
\end{tabular}




\subsection{Numerical modeling}

Computational simulations were performed using the Senkin code [43] of the Chemkin II package [44] or Cantera [45], through a numerical procedure implemented in Matlab. Three state-of-the-art detailed reaction mechanisms were evaluated: (i) CaltechMech [46] (1159 reactions and 192 species), (ii) GalwayMech [32] (4150 reactions and 913 species), and (iii) LLNLMech [47] (2834 reactions and 661 species). The sub-mechanisms of the electronically excited species containing $\mathrm{OH}^{*}, \mathrm{CH}^{*}$ and $\mathrm{CO}_{2}{ }^{*}$ [40] were added to each mechanism in order to reproducing ignition delay times measured by emission diagnostics in the ST. A constant volume reactor was used to predict the ignition delay times in shock tube. For the RCM experiments, the ignition delay time is long enough to be affected by heat losses after the end of the compression. Hence, a variable volume reactor model was employed as in [48]. A series of non-reactive experiments were performed in which oxygen was replaced by nitrogen to avoid ignition. These experiments enabled the determination of the equivalent specific volume profiles by measuring the pressure in the test section and assuming an adiabatic isentropic expansion process is taking place after the end of compression.

\subsection{Evaluation of reaction model performance}

In order to quantitatively evaluate the predictive capability of the three chemical kinetic mechanisms, a number of indicators have been calculated.

The relative error of the $i^{\text {th }}$ experimental data point $\left(E_{i}\right)$ enables to evaluate the local performance of the models, that is for a single data point. It was calculated as

$$
E_{i}=\frac{\tau_{\text {model }}^{i}-\tau_{\text {expe }}^{i}}{\tau_{\text {expe }}^{i}} \times 100
$$

where $\tau_{\text {expe }}^{i}$ and $\tau_{\text {model }}^{i}$ are the experimental and numerical ignition delay time for the $i^{\text {th }}$ data point, respectively.

In order to evaluate the overall performance of the mechanisms, the mean and the maximum absolute errors were calculated. The expression of the mean absolute 
error $(\mu)$ was

$$
\mu=\frac{1}{N} \sum_{i=1}^{n}\left|E_{i}\right|
$$

where $N$ is the total number of experimental data points. The maximum absolute error $\left(E_{\text {max }}\right)$ was

$$
E_{\max }=\max \left(\left|E_{i=1, \ldots, N}\right|\right)
$$

A more detailed evaluation of the mechanisms performance, was obtained by calculating the distribution of relative error. Bins of $10 \%$ were employed. The relative population for the $j^{\text {th }}$ bin, $R P_{j}$, is expressed by

$$
R P_{j}=\frac{n_{j}}{N}
$$

where $n_{j}$ is the number of data points that conforms to

$$
\left|E_{j}-v_{j}\right|<5 \%
$$

where $v_{j}$ denotes the central value of the $j^{\text {th }}$ bin.

\section{Results and discussion}

\subsection{Low- and intermediate-temperature ignition in $R C M$}

\subsubsection{Experimental results and reaction models performance}

Figure 2 shows the effects of n-hexane concentration, pressure, and equivalence ratio on the ignition delay time of methane-n-hexane-oxygen-diluent mixtures. Twostage ignition was observed for all mixtures and conditions within the temperature range $700-820 \mathrm{~K}$ and corresponds to a characteristic feature of the ignition of $\mathrm{n}$ hexane-based mixtures. In addition, the negative temperature coefficient (NTC) behavior of the total ignition was observed in all the experimental conditions except for Mixture 2 at $2 \mathrm{MPa}$ (shown in Figure 3(b)). This is because at higher pressure and n-hexane content, the NTC region is shifted beyond the accessible ranges of temperature and ignition delay time of our facility. The increase of n-hexane content from $10 \%$ to $20 \%$ dramatically shortens the first-stage and total ignition delay time by a factor of 3 to 4 over the temperature range studied (see Figure 2(a)). The increase of pressure from 1 to $2 \mathrm{MPa}$ reduces the first-stage and total ignition delay 
time by a factor of 2 , and 3 to 5 for temperatures above $700 \mathrm{~K}$, respectively. There is no evident effect of pressure for temperatures lower than $700 \mathrm{~K}$ (see Figure 2(b)). Equivalence ratio only affects the total ignition delay for temperature above $750 \mathrm{~K}$ with a decrease of approximately a factor of 2 as equivalence ratio is increased from 0.5 to 1 (see Figure 2(c)). It is noteworthy that the effects of pressure and equivalence ratio occur for temperatures above $700-750 \mathrm{~K}$, whereas the effect of n-hexane addition on ignition delay time is observed over the entire temperature range. To underline the effect of fuel blending, we have calculated the adiabatic constant volume delay-time at $\mathrm{P}=1 \mathrm{MPa}$ and $\mathrm{T}=745 \mathrm{~K}$ for a stoichiometric methane-oxygen-nitrogenargon mixture and a stoichiometric n-hexane-oxygen-nitrogen-argon mixture. For these calculations performed with the LLNLMech, the dilution ratio was the same as for fuel-air mixtures and ratio $\mathrm{X}_{A r} / \mathrm{X}_{N 2}$ was 4.28 as in our experiments. The delay-time for the methane-based mixture was $6.35 \mathrm{~s}$, whereas the delay-time for the n-hexane-based mixture was $11.2 \mathrm{~ms}$ (3.1 ms for the first stage). These results should be interpreted with care because the calculated delay-time for the methanebased mixture is essentially extrapolated from a much higher temperature range over which methane combustion is typically studied. This indicates that, in the low-temperature range, the ignition characteristics of the most reactive fuel seem to dominate the ignition process of the dual-fuel mixture.

Figure 3 shows representative comparisons between the measured and predicted ignition delay times. Additional modeling results for the LLNLMech are shown in Figure 2. The three mechanisms reproduce the main trends experimentally measured but significant quantitative discrepancies are observed with relative error as high as $300 \%$ under certain conditions. Table 2 summarizes the performances of the mechanisms by presenting the mean and maximum absolute error on the first-stage and total ignition delay time. Overall, CaltechMech and GalwayMech overestimate both first-stage and total ignition delay time, especially below $725 \mathrm{~K}$, while LLNLMech better predicts both the first-stage and total ignition with a mean absolute error on the first-stage and total ignition delay times of $64.58 \%$ and $24.35 \%$, respectively. 


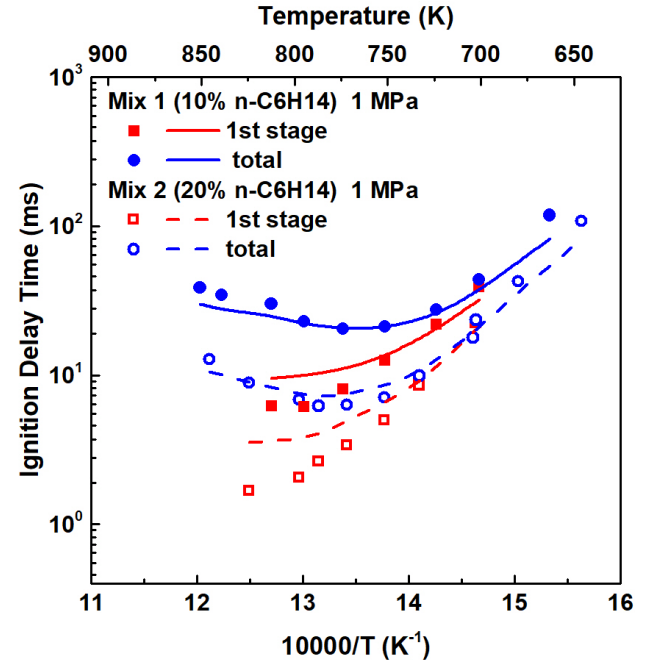

(a) Effect of n-hexane concentration

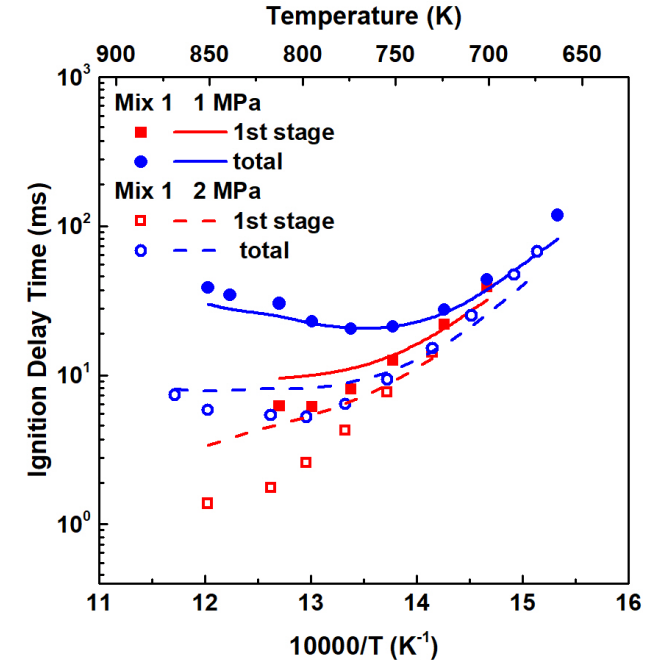

(b) Effect of pressure

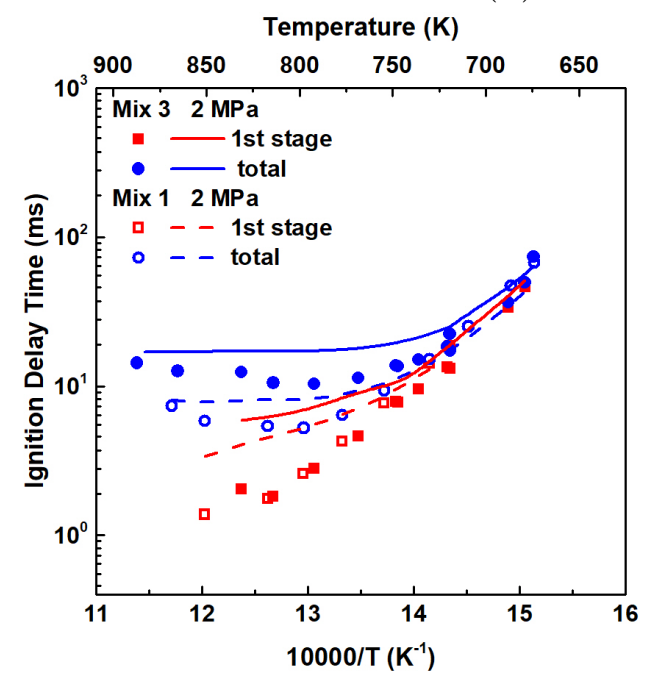

(c) Effect of equivalence ratio

Figure 2: Effect of n-hexane concentration (a), pressure (b) and equivalence ratio (c) on the first-stage and total ignition delay time of for $\mathrm{CH}_{4}-\mathrm{C}_{6} \mathrm{H}_{14}-\mathrm{O}_{2}$-diluent mixtures in a RCM. Lines correspond to the predictions of the LLNLMech. 

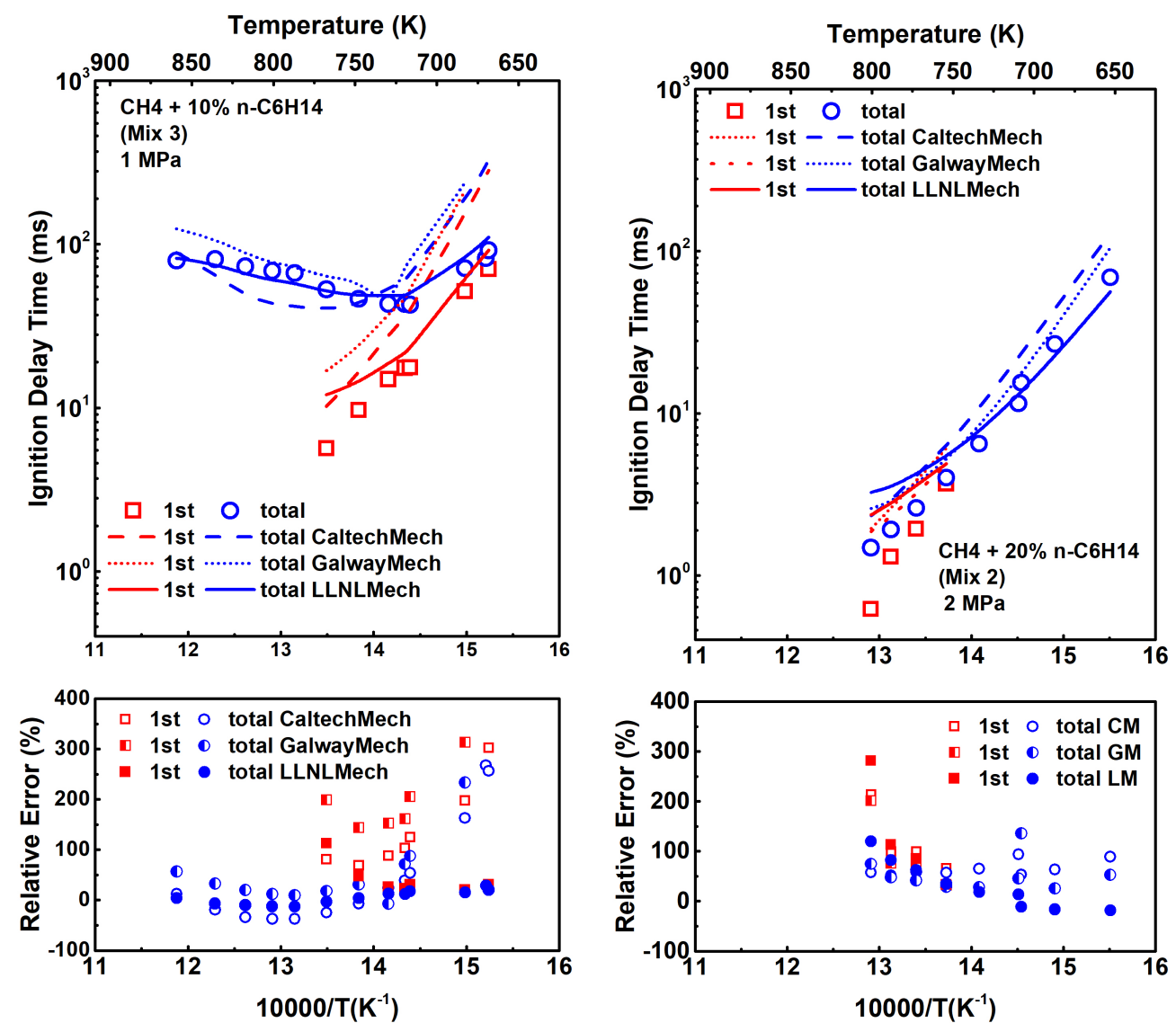

(a) Low n-hexane content

(b) High n-hexane content

Figure 3: Representative comparisons between the experimental and numerical first-stage and total ignition delay time for (a) Mixture 3 at $1 \mathrm{MPa}$ and (b) Mixture 2 at $2 \mathrm{MPa}$ in a RCM. In bottom plots, CM: CaltechMech; GM: GalwayMech; LM: LLNLMech. 
Figure 4 shows the relative population $(R P)$ of error for the first-stage and total ignition delay times. For first-stage ignition, the distribution of $R P$ for all the mechanisms are centered on positive values which indicates an overall over-estimation. This implies that future work need to be focused on improving the predictive capability for first-stage ignition. As previously seen from the other quantitative indicators, LLNLMech demonstrates lower error. Concerning the total ignition delay, CaltechMech demonstrates a broad distribution whereas GalwayMech exhibits a distribution centered on approximately 50\% error. Only LLNLMech exhibits a distribution of $R P$ centered approximately on zero.

Table 2: Mean and maximum absolute error on the first-stage and total ignition delay time predicted by the three reaction models for $\mathrm{CH}_{4}-\mathrm{C}_{6} \mathrm{H}_{14}-\mathrm{O}_{2}$-diluent mixtures under RCM conditions.

\begin{tabular}{ccccccc} 
Ignition & \multicolumn{2}{c}{ CaltechMech } & \multicolumn{2}{c}{ GalwayMech } & \multicolumn{2}{c}{ LLNLMech } \\
delay time & Mean \% & Max \% & Mean \% & Max \% & Mean \% & Max \% \\
\hline First-stage & 68.94 & 303.05 & 99.17 & 313.81 & 64.58 & 281.44 \\
Total & 47.39 & 268.00 & 48.72 & 233.32 & 24.35 & 119.75 \\
\hline
\end{tabular}

\subsubsection{Chemical kinetic analyses}

Since the present work mainly focuses on the effect of n-hexane addition on the ignition delay time of methane-oxygen mixtures, chemical kinetic analyses were performed by comparing the modeling results between Mixture 1 (10\% n-hexane) and Mixture $2(20 \%$ n-hexane) at $P=1 \mathrm{MPa}$ and $T=745 \mathrm{~K}$. The temperature of $745 \mathrm{~K}$ was chosen because it is approximately the center of the temperature range investigated with the RCM and because, at this temperature, noticeable differences (approximately a factor of 3 for the total ignition delay) were observed between the delay times obtained for Mixtures 1 and 2. Due to its better performances at reproducing the RCM experimental data, the LLNLMech was employed for all the analyses.

The results of the sensitivity analysis performed on temperature are shown in Figure 5(a). It is noted that the sensitivity coefficients have been integrated over 

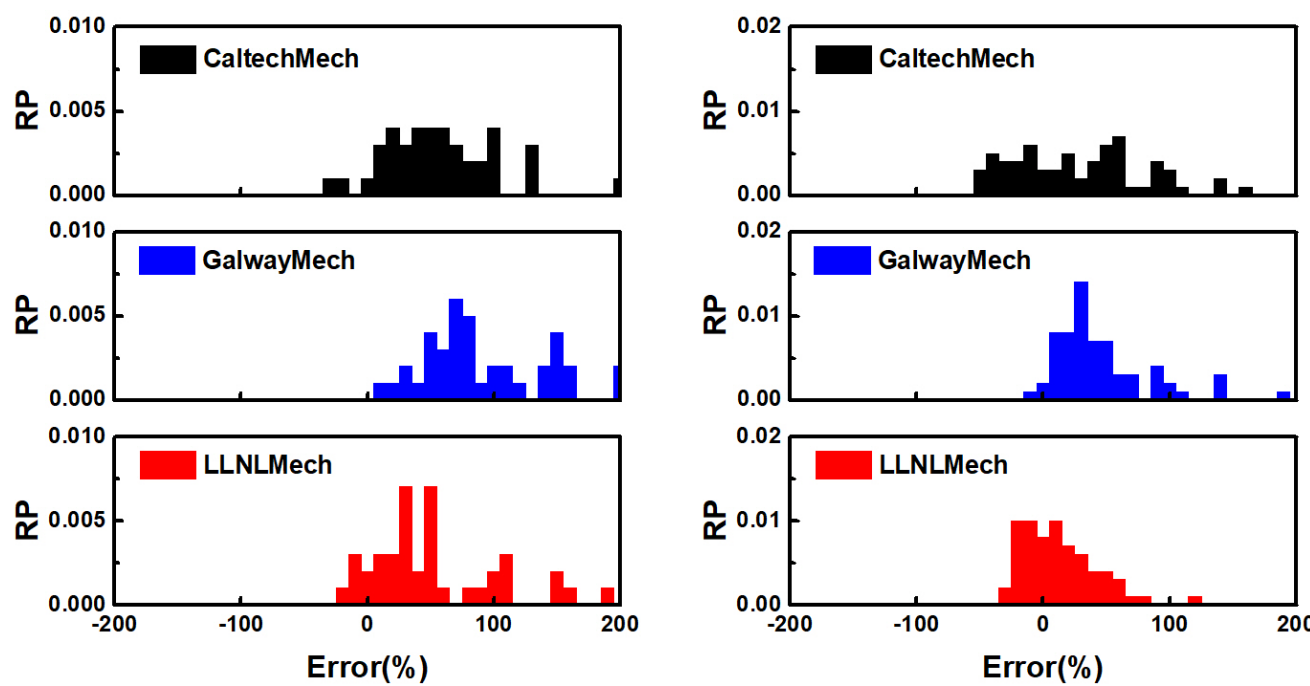

(a) Error on first stage ignition delay

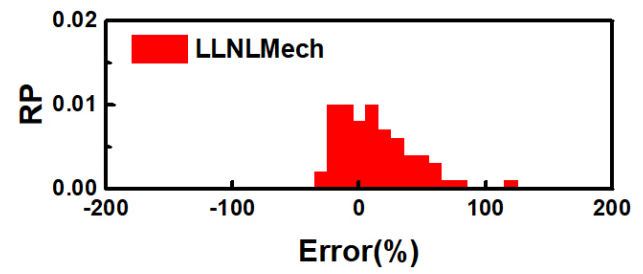

(b) Error on total ignition delay

Figure 4: Relative population $(R P)$ of relative error on (a) the first stage and (b) the total ignition delay time predicted by the three chemical kinetic mechanisms for $\mathrm{CH}_{4}-\mathrm{C}_{6} \mathrm{H}_{14}-\mathrm{O}_{2}$-diluent mixtures under RCM conditions.

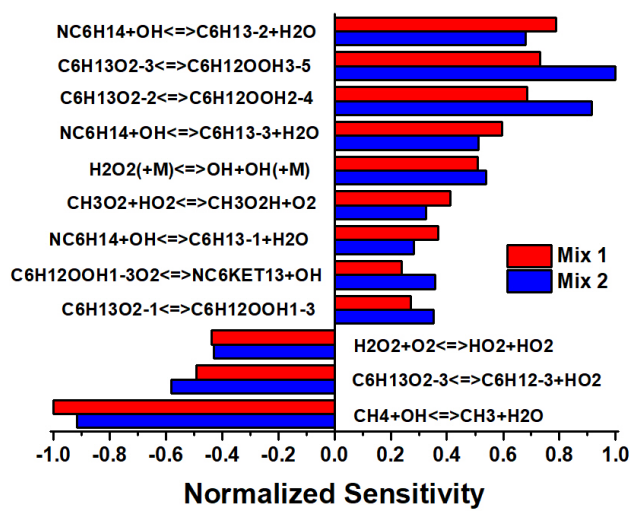

(a) Sensitivity coefficient

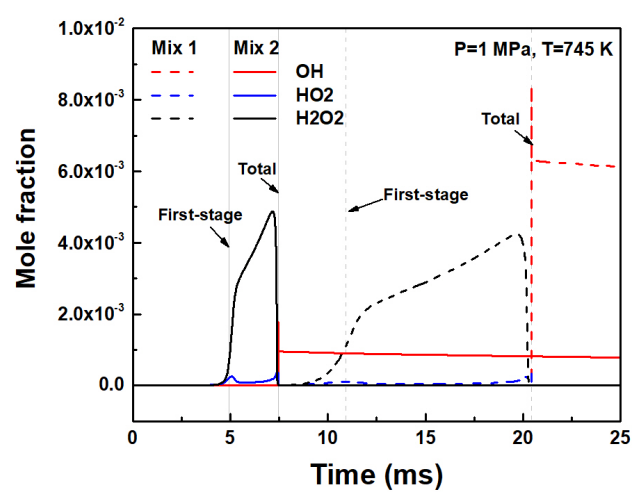

(b) Radical profiles

Figure 5: Comparison of (a) the sensitivity coefficients on temperature and (b) $\mathrm{OH}, \mathrm{HO}_{2}$ and $\mathrm{H}_{2} \mathrm{O}_{2}$ mole fraction profiles between Mixture 1 (10\% n-hexane) and Mixture $2(20 \%$ n-hexane $)$ at $P=1$ MPa and $T=745 \mathrm{~K}$. Calculations were performed with the LLNLMech. 
the full time of the simulation. The sensitivity coefficient on temperature for the $i^{\text {th }}$ reaction is defined as

$$
C_{i}=\frac{\partial \ln T}{\partial \ln k_{i}}=\frac{k_{i}}{T} \frac{\partial T}{\partial k_{i}}
$$

where $k_{i}$ is the rate constant of reaction $i$. A positive coefficient indicates a reaction that promotes ignition, and a negative one indicates a reaction that delays ignition. The reactions which exhibit the highest positive coefficients are almost all related to the low-temperature oxidation of n-hexane. This demonstrates the primary influence of the n-hexane addition to the mixture on the ignition process. With the increase of n-hexane addition from 10 to $20 \%$, the sensitivity coefficients for the isomerization reactions $\mathrm{C}_{6} \mathrm{H}_{13} \mathrm{O}_{2}-3=\mathrm{C}_{6} \mathrm{H}_{12} \mathrm{OOH} 3-5$ and $\mathrm{C}_{6} \mathrm{H}_{13} \mathrm{O}_{2}-2=\mathrm{C}_{6} \mathrm{H}_{12} \mathrm{OOH} 2-4$ increase and overcome that of the $\mathrm{H}$ abstraction reaction $\mathrm{NC}_{6} \mathrm{H}_{14}+\mathrm{OH}=\mathrm{C}_{6} \mathrm{H}_{13}-2+\mathrm{H}_{2} \mathrm{O}$. The sensitivity coefficients of isomerization reaction $\mathrm{C}_{6} \mathrm{H}_{13} \mathrm{O}_{2}-1=\mathrm{C}_{6} \mathrm{H}_{12} \mathrm{OOH} 1-3$ and its subsequent decomposition reaction $\mathrm{C}_{6} \mathrm{H}_{12} \mathrm{OOH} 1-3 \mathrm{O}_{2}=\mathrm{NC}_{6} \mathrm{KET} 13+\mathrm{OH}$ also increase. The decomposition reaction $\mathrm{H}_{2} \mathrm{O}_{2}(+\mathrm{M})=\mathrm{OH}+\mathrm{OH}(+\mathrm{M})$ and the chain terminating reaction $\mathrm{HO}_{2}+\mathrm{HO}_{2}=\mathrm{H}_{2} \mathrm{O}_{2}+\mathrm{O}_{2}$ exhibit high sensitivity. This indicates that $\mathrm{OH}, \mathrm{HO}_{2}$, and $\mathrm{H}_{2} \mathrm{O}_{2}$ play critical roles in the ignition process of methane-oxygen mixture with n-hexane addition. Note that the species names we employed correspond to those used in the LLNLMech. We have provided the names and structures of these molecules as a supplemental material.

Figure 5(b) compares the $\mathrm{OH}, \mathrm{HO}_{2}$, and $\mathrm{H}_{2} \mathrm{O}_{2}$ profiles predicted for Mixture $1(10 \%$ n-hexane) and Mixture 2 (20\% n-hexane). There is an accumulation of $\mathrm{H}_{2} \mathrm{O}_{2}$ between the first-stage and total ignition delay time, and this is due to the conversion of $\mathrm{HO}_{2}$ radical to $\mathrm{H}_{2} \mathrm{O}_{2}$ by $\mathrm{HO}_{2}+\mathrm{HO}_{2}=\mathrm{H}_{2} \mathrm{O}_{2}+\mathrm{O}_{2}$. Then, the decomposition of $\mathrm{H}_{2} \mathrm{O}_{2}$ generates a large amount of $\mathrm{OH}$ radical inducing the second-stage ignition. This chemical sequence explains the high sensitivity coefficient of these two reactions.

Figure 6 shows the rate of production (ROP) profiles for $\mathrm{HO}_{2}$ and $\mathrm{OH}$ radicals production during the first-stage and total ignition for Mixture 1 (10\% n-hexane) and Mixture 2 (20\% n-hexane).

Concerning $\mathrm{HO}_{2}$, before the first-stage ignition, the reactions of oxygen with $\mathrm{HCO}$ and $\mathrm{CH}_{3} \mathrm{O}$, which originate from the low-temperature n-hexane oxidation, initiate the production of $\mathrm{HO}_{2}$ radical. Between the first-stage and total ignition delay time, 

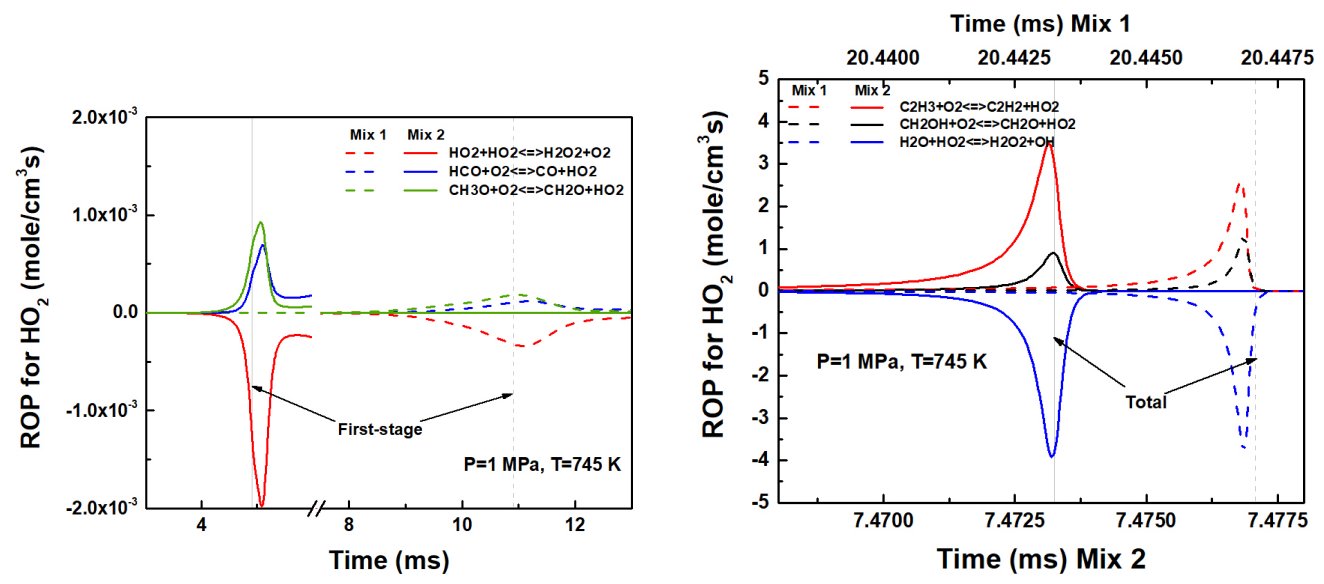

(a) $\mathrm{HO}_{2}$ during first-stage ignition

(b) $\mathrm{HO}_{2}$ during second-stage ignition
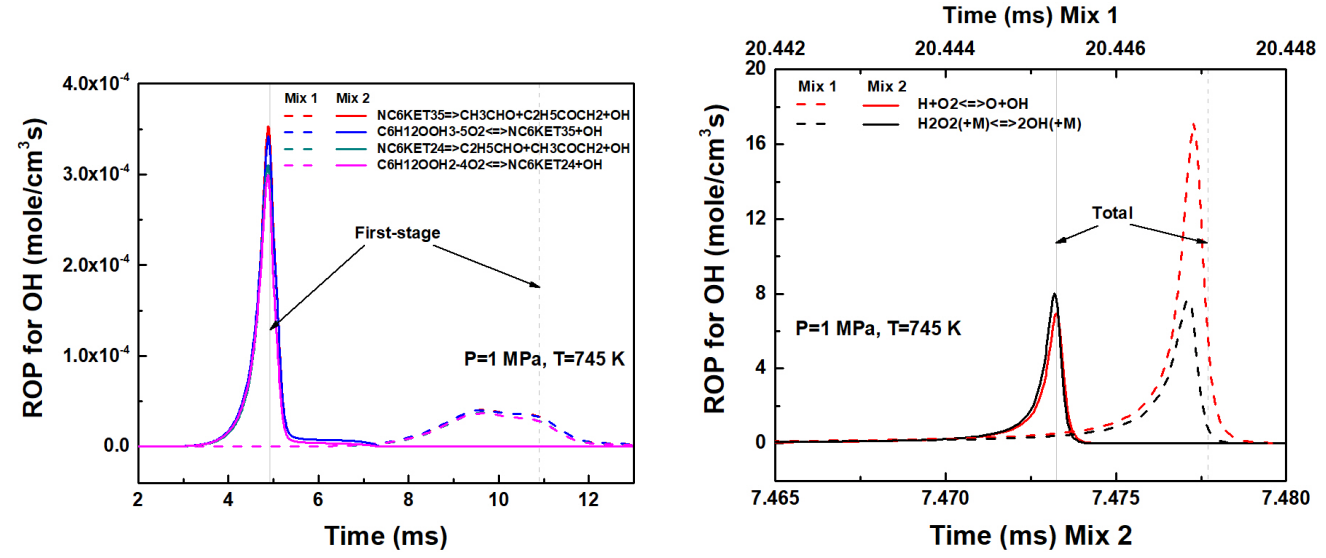

(c) $\mathrm{OH}$ during first-stage ignition

(d) $\mathrm{OH}$ during second-stage ignition

Figure 6: Comparison of the key reactions for $\mathrm{HO}_{2}$ (a) (b) and $\mathrm{OH}$ (c) (d) radical production profiles during first-stage and second-stage ignition between Mixture 1 (10\% n-hexane) and Mixture 2 (20\% n-hexane) at $P=1 \mathrm{MPa}$ and $T=745 \mathrm{~K}$. Calculations were performed with the LLNLMech. 
reactions between oxygen and $\mathrm{C}_{2} \mathrm{H}_{3}, \mathrm{CH}_{2} \mathrm{OH}$ are responsible for the production of $\mathrm{HO}_{2}$ radical. Simultaneously, a large amount of $\mathrm{HO}_{2}$ radical is converted into $\mathrm{H}_{2} \mathrm{O}_{2}$ through $\mathrm{HO}_{2}+\mathrm{HO}_{2}=\mathrm{H}_{2} \mathrm{O}_{2}+\mathrm{O}_{2}$ and $\mathrm{HO}_{2}+\mathrm{H}_{2} \mathrm{O}=\mathrm{H}_{2} \mathrm{O}_{2}+\mathrm{OH}$. These explain the accumulation of $\mathrm{H}_{2} \mathrm{O}_{2}$ between the fist-stage and total ignition delay time. Besides, all the reactions abovementioned are enhanced by increasing the amount of n-hexane.

As for $\mathrm{OH}$ radical, during the first-stage ignition, the production of $\mathrm{OH}$ radical is mainly due to (i) the $\mathrm{OH}$ elimination reactions involving $\mathrm{C}_{6} \mathrm{H}_{12} \mathrm{OOH} 3-5 \mathrm{O}_{2}$ and $\mathrm{C}_{6} \mathrm{H}_{12} \mathrm{OOH} 2-4 \mathrm{O}_{2}$, and (ii) the decomposition reactions of $\mathrm{NC}_{6} \mathrm{KET} 35$ and $\mathrm{NC}_{6} \mathrm{KET} 24$. These latter reactions are the subsequent steps of the isomerization reactions and exhibit high sensitivity coefficient as previously mentioned. These four reactions are enhanced by the increased amount of n-hexane in the mixture. For total ignition, chain branching reaction $\mathrm{H}+\mathrm{O}_{2}=\mathrm{O}+\mathrm{OH}$ and $\mathrm{H}_{2} \mathrm{O}_{2}$ decomposition reaction $\mathrm{H}_{2} \mathrm{O}_{2}$ $(+\mathrm{M})=\mathrm{OH}+\mathrm{OH}(+\mathrm{M})$ dominate the production of $\mathrm{OH}$ radical. Moreover, the increasing addition of n-hexane from 10 to $20 \%$ promotes the $\mathrm{OH}$ radical production rate of $\mathrm{H}_{2} \mathrm{O}_{2}(+\mathrm{M})=\mathrm{OH}+\mathrm{OH}(+\mathrm{M})$ which overcomes that of $\mathrm{H}+\mathrm{O}_{2}=\mathrm{O}+\mathrm{OH}$.

We also performed an analysis of the rate of production for $\mathrm{CH}_{4}$. The results of this analysis are shown in Figure 7. During the first ignition stage, the consumption of $\mathrm{CH}_{4}$ is only due to $\mathrm{CH}_{4}+\mathrm{OH}=\mathrm{CH}_{3}+\mathrm{H}_{2} \mathrm{O}$. During the second ignition stage, the consumption of methane is distributed between $\mathrm{CH}_{4}+\mathrm{OH}=\mathrm{CH}_{3}+\mathrm{H}_{2} \mathrm{O}$ and $\mathrm{CH}_{4}+\mathrm{H}=\mathrm{CH}_{3}+\mathrm{H}_{2}$.

Based on the sensitivity and rate of production analyses performed, the effect of n-hexane addition on the ignition delay time of methane-oxygen mixtures is due to the low-temperature chemistry of n-hexane. Chemical pathways not available for methane oxidation become more and more important as n-hexane content is increased and result in the production of active radicals, mainly $\mathrm{OH}$, which accelerates the ignition of the methane-oxygen mixtures. More precisely, the main chemical sequences responsible for the first-stage ignition are $\mathrm{C}_{6} \mathrm{H}_{13} \mathrm{O}_{2}-3 \rightarrow \mathrm{C}_{6} \mathrm{H}_{12} \mathrm{OOH} 3-5 \rightarrow$ $\mathrm{C}_{6} \mathrm{H}_{12} \mathrm{OOH} 3-5 \mathrm{O}_{2} \rightarrow \mathrm{NC}_{6} \mathrm{KET} 35$ and $\mathrm{C}_{6} \mathrm{H}_{13} \mathrm{O}_{2}-2 \rightarrow \mathrm{C}_{6} \mathrm{H}_{12} \mathrm{OOH} 2-4 \rightarrow \mathrm{C}_{6} \mathrm{H}_{12} \mathrm{OOH} 2-$ 
$4 \mathrm{O}_{2} \rightarrow \mathrm{NC}_{6} \mathrm{KET} 24$; while the decomposition of $\mathrm{H}_{2} \mathrm{O}_{2}$ is responsible for the secondstage ignition.

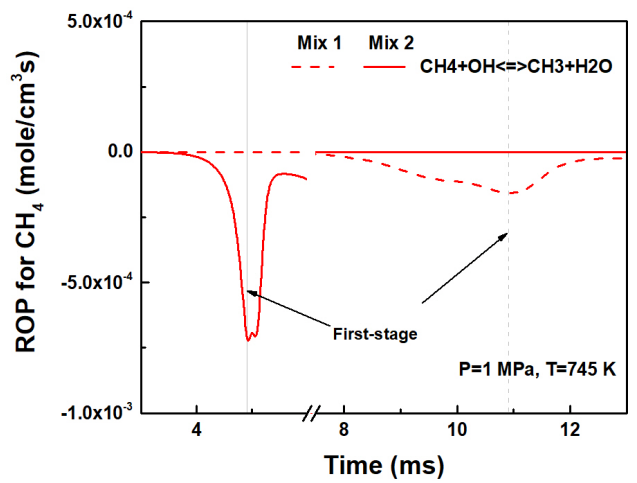

(a) First-stage ignition

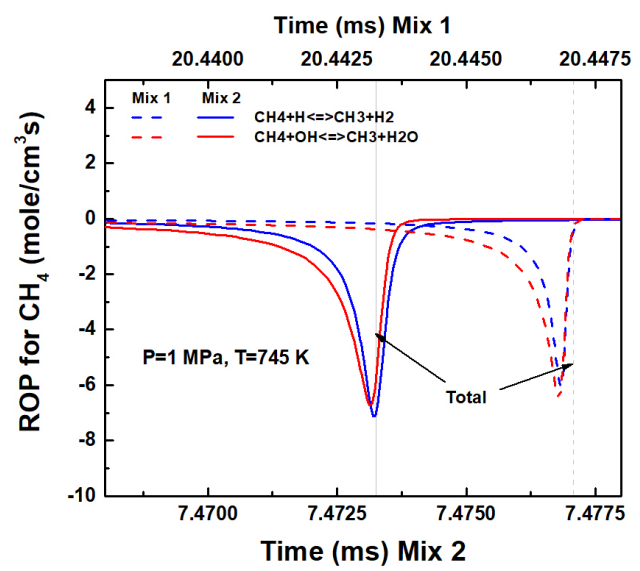

(b) Second-stage ignition

Figure 7: Comparison of the key reactions for $\mathrm{CH}_{4}$ during first-stage and second-stage ignition between Mixture 1 (10\% n-hexane) and Mixture 2 (20\% n-hexane) at $P=1 \mathrm{MPa}$ and $T=745 \mathrm{~K}$. Calculations were performed with the LLNLMech.

\subsection{High-temperature ignition in $S T$}

\subsubsection{Experimental results and reaction models performance}

Figure 8 to 10 show the ignition delay times obtained in ST based on $\mathrm{OH}^{*}$ as well as comparisons with the predictions of the three chemical kinetic mechanisms. Results based on $\mathrm{CH}^{*}$ and $\mathrm{CO}_{2}{ }^{*}$ are provided in the supplementary material.

Methane exhibits much longer ignition delay times than n-hexane, which is in accordance with previous experimental data [49]. With respect to the methane-nhexane mixtures, the ignition delay time decreases as temperature increases and no negative temperature coefficient behavior was observed in current high-temperature range. There is a distinguishable effect caused by the addition of $10 \%$ n-hexane, which shortens the ignition delay time dramatically. It is compelling that a sharp decrease by a factor of 5 to 7 was observed under fuel-lean conditions. Nevertheless, no further influence can be exerted in reducing the ignition delay time when increasing the addition of n-hexane from $10 \%$ to $20 \%$ as shown in Figure 8 . From a different 

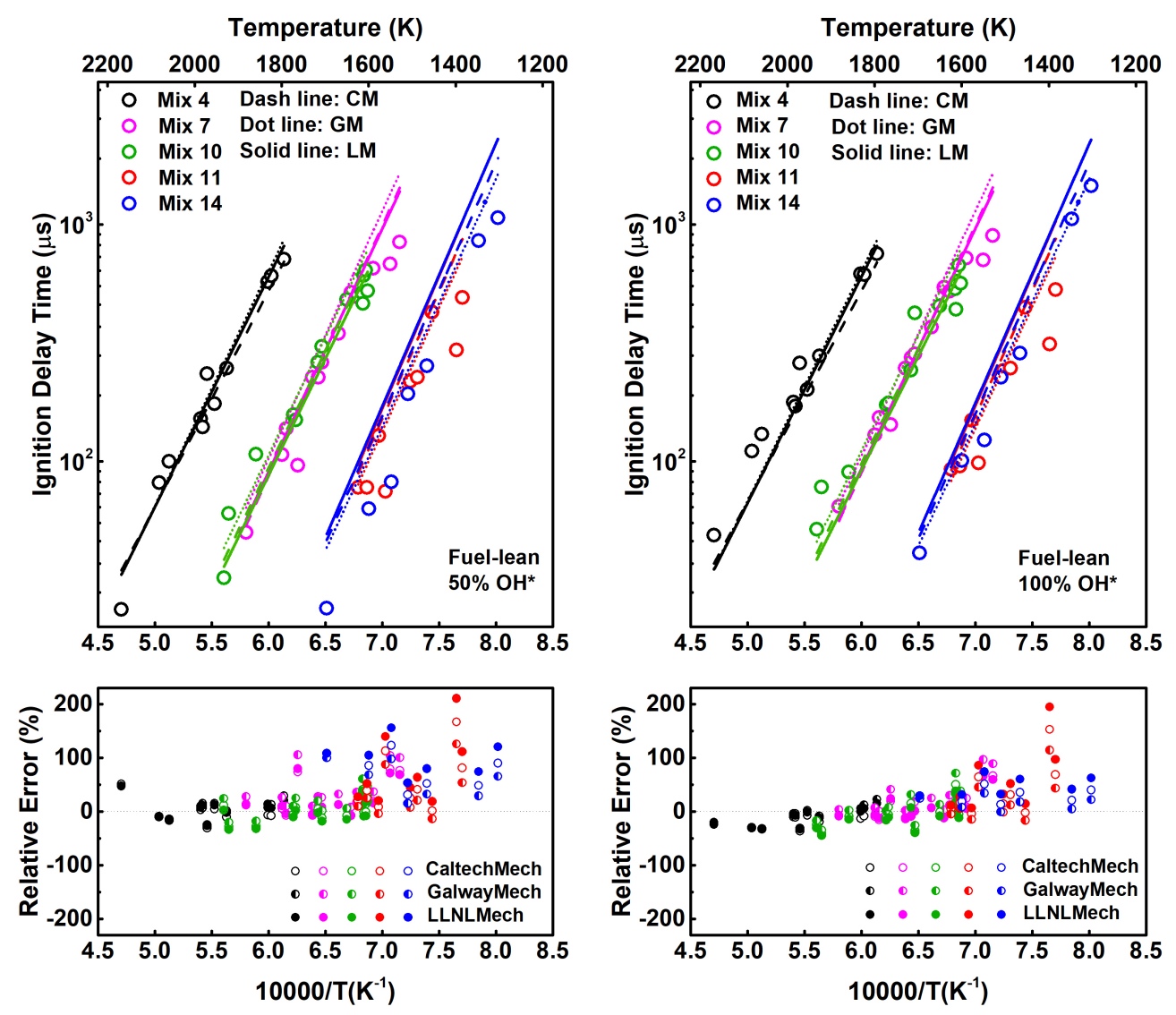

(a) $\tau_{50}$

(b) $\tau_{100}$

Figure 8: Comparisons between the experimental and numerical ignition delay time based on $\mathrm{OH}^{*}$ emissions for lean $\mathrm{CH}_{4}-\mathrm{C}_{6} \mathrm{H}_{14}-\mathrm{O}_{2}$-diluent mixtures. CM: CaltechMech model; GM: GalwayMech; LM: LLNLMech. 
perspective, comparing the n-hexane with and without methane addition, it is noteworthy that no perceptible effect can be achieved by the addition of $10 \%$ methane to n-hexane. These imply that n-hexane with high reactivity overwhelmingly dominates the ignition characteristics of methane-n-hexane mixtures when it exceeds a certain amount. Regarding the effect of equivalence ratio, the effect of n-hexane addition in shortening the ignition delay time weakens for stoichiometric and rich mixtures, see Figure 9 and 10. This can be attributed to the self-inhibition property of hydrocarbons on the ignition process in the high-temperature range [40, 31].
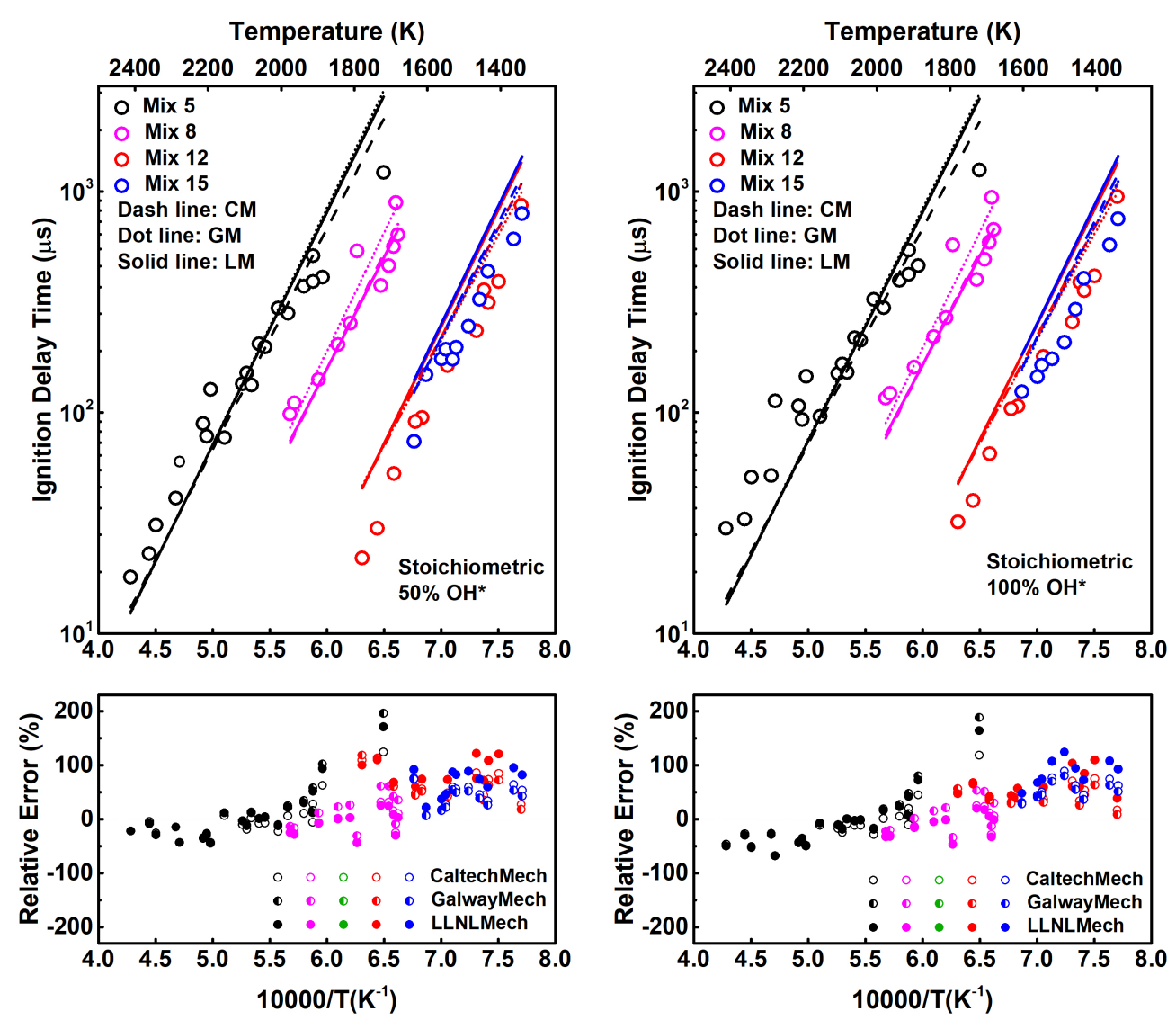

(a) $\tau_{50}$

(b) $\tau_{100}$

Figure 9: Comparisons between the experimental and numerical ignition delay time based on $\mathrm{OH}^{*}$ emissions for stoichiometric $\mathrm{CH}_{4}-\mathrm{C}_{6} \mathrm{H}_{14}-\mathrm{O}_{2}$-diluent mixtures. CM: CaltechMech model; GM: GalwayMech; LM: LLNLMech. 

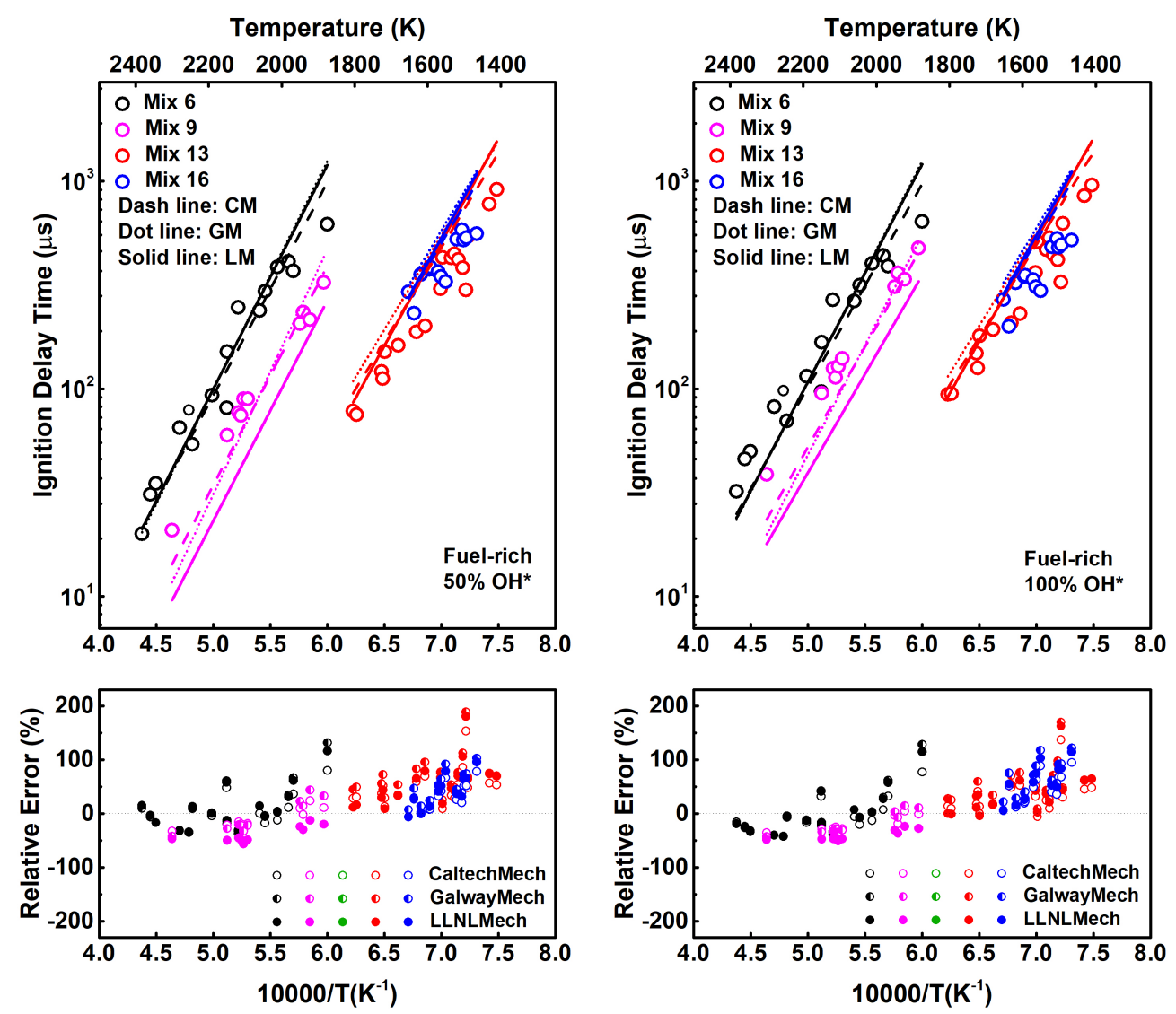

(a) $\tau_{50}$

(b) $\tau_{100}$

Figure 10: Comparisons between the experimental and numerical ignition delay time based on $\mathrm{OH}^{*}$ emissions for rich $\mathrm{CH}_{4}-\mathrm{C}_{6} \mathrm{H}_{14}-\mathrm{O}_{2}$-diluent mixtures. CM: CaltechMech model; GM: GalwayMech; LM: LLNLMech.

Table 3: Mean and maximum absolute error on the high-temperature ignition delay time predicted by the three reaction models under ST conditions for $\mathrm{CH}_{4}-\mathrm{C}_{6} \mathrm{H}_{14}-\mathrm{O}_{2}-\mathrm{Ar}$ mixtures.

\begin{tabular}{ccccccc}
\hline & \multicolumn{2}{c}{ CaltechMech } & \multicolumn{2}{c}{ GalwayMech } & \multicolumn{2}{c}{ LLNLMech } \\
& Mean \% & Max \% & Mean \% & Max \% & Mean \% & Max \% \\
\hline Ignition & & & & & & \\
delay time & 32.61 & 166.76 & 37.67 & 196.14 & 41.196 & 210.77 \\
\hline
\end{tabular}

All three chemical kinetic mechanisms capture the main experimental features but significant deviations can be observed with relative error as high as $200 \%$ under certain conditions. Overall, GalwayMech and LLNLMech overestimate the ignition delay time more than CaltechMech, especially for mixtures with n-hexane under 
stoichiometric and fuel-rich conditions. Table 3 demonstrates the predictive performance of the three mechanisms by listing the mean and maximum absolute error on the measured ignition delay times of all the 13 mixtures based on $\mathrm{OH}^{*}, \mathrm{CH}^{*}$ and $\mathrm{CO}_{2}{ }^{*}$ emission diagnostics. CaltechMech exhibits a better predictive capability of the high-temperature ignition delay time with a mean absolute error of $32.61 \%$. Figure 11 shows the relative population of relative error for the ignition delay time and it can be seen that CaltechMech exhibits a distribution of $R P$ centered much closer to zero as compared to the other two mechanisms.

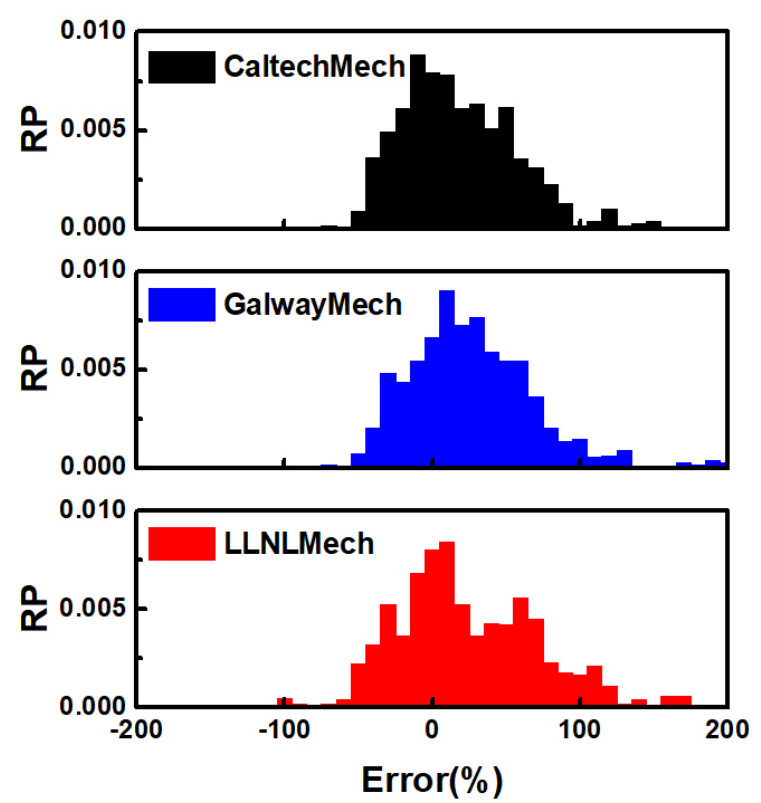

Figure 11: Relative population $(R P)$ of relative error on ignition delay time in shock tube predicted by the three chemical kinetic mechanisms for $\mathrm{CH}_{4}-\mathrm{C}_{6} \mathrm{H}_{14}-\mathrm{O}_{2}$ - $\mathrm{Ar}$ mixtures under ST conditions.

\subsubsection{Chemical kinetic analyses}

In order to gain further insight into the effect of n-hexane addition on the ignition of methane-oxygen mixtures at high temperature, chemical kinetic analyses were conducted for Mixture 5 (methane) and Mixture 8 (methane and 10\% n-hexane) at $P=0.3 \mathrm{MPa}$ and $T=1700 \mathrm{~K}$. This temperature was chosen because it corresponds approximately to the lowest and highest temperature for the experiments performed with methane and n-hexane as the only fuel, respectively. Due to its higher performance in reproducing the ST data, CaltechMech was adopted to perform these 
analyses of the effect of n-hexane addition on high-temperature ignition delay time.

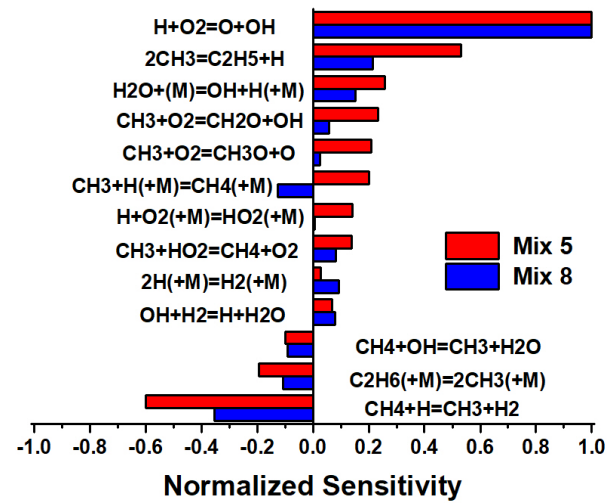

(a) Sensitivity coefficient

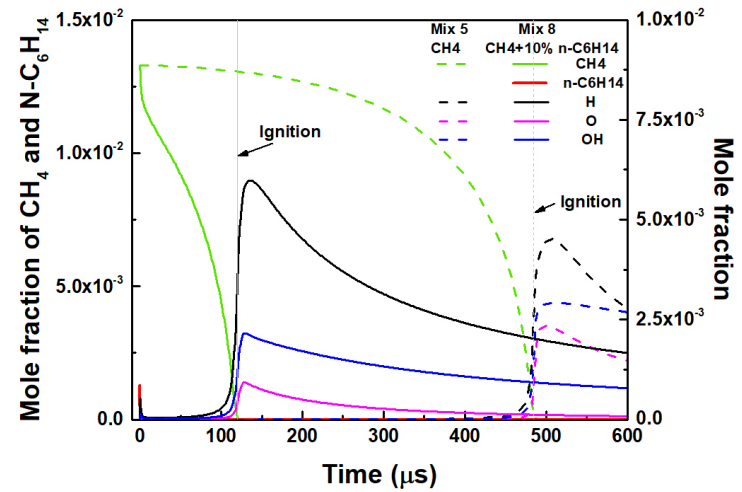

(b) Species profiles

Figure 12: Comparison (a) of the sensitivity coefficients on temperature and (b) of the $\mathrm{H}, \mathrm{O}, \mathrm{OH}$, $\mathrm{CH}_{4}$, and $n-\mathrm{C}_{6} \mathrm{H}_{14}$ mole fraction profiles between Mixture 5 (methane) and Mixture 8 (methane and $10 \%$ n-hexane) at $P=0.3 \mathrm{MPa}$ and $T=1700 \mathrm{~K}$. Calculations were performed with the CaltechMech.

The normalized sensitivity coefficients on temperature (see Equation 9) are compared in Figure 12 (a). It is noted that the sensitivity coefficients have been integrated over the full time of the simulation. For both conditions, the chain branching reaction $\mathrm{H}+\mathrm{O}_{2}=\mathrm{O}+\mathrm{OH}$ exhibits an overwhelmingly high positive sensitivity coefficient due to its critical role in inducing the ignition. For all the $\mathrm{CH}_{4^{-}}$and $\mathrm{CH}_{3}$-related reactions, either with positive or negative sensitivity coefficients, the sensitivity coefficients decrease dramatically when $10 \%$ n-hexane is added. The coefficient even changes from positive to negative for reaction $\mathrm{CH}_{3}+\mathrm{H}(+\mathrm{M})=\mathrm{CH}_{4}$ $(+\mathrm{M})$. These imply that the n-hexane addition weakens the influence of methane on the ignition process. Besides, the sensitivity coefficients of H-related reactions $2 \mathrm{H}$ $(+\mathrm{M})=\mathrm{H}_{2}(+\mathrm{M})$ and $\mathrm{OH}+\mathrm{H}_{2}=\mathrm{H}+\mathrm{H}_{2} \mathrm{O}$ are increased by the n-hexane addition. Figure 12 (b) compares the $\mathrm{H}, \mathrm{O}, \mathrm{OH}, \mathrm{CH}_{4}$ and $\mathrm{n}-\mathrm{C}_{6} \mathrm{H}_{14}$ mole fraction profiles between Mixture 5 (methane) and Mixture 8 (methane and 10\% n-hexane). Both the time scale and the evolution of the species profiles are quite different for the two mixtures. For Mixture 5, the concentration of methane decreases very slowly during the initial stage of the reaction and most of methane is consumed at a time close to ignition as the rate of methane removal becomes faster and faster. For Mixture 8, an initial rapid drop of the methane mole fraction is observed as n-hexane is 
decomposed within few $\mu s$. The rate of methane consumption then decreases for approximately $50 \mu s$ and finally, increases again as the concentration of active radicals starts to increase just before ignition is taking place. Concerning the radical pool, the n-hexane addition induces a rapid production of $\mathrm{H}, \mathrm{O}$ and $\mathrm{OH}$ radicals during the initial stage of the ignition process which is not observed for Mixture 5. In addition, the addition of n-hexane induces an increase of the peak concentration of $\mathrm{H}$ atom and a decrease of the peak concentration of $\mathrm{O}$ and $\mathrm{OH}$. These imply the prominent importance of the rapid decomposition of n-hexane in producing active radicals, especially $\mathrm{H}$, to accelerate the ignition of methane-oxygen mixtures.

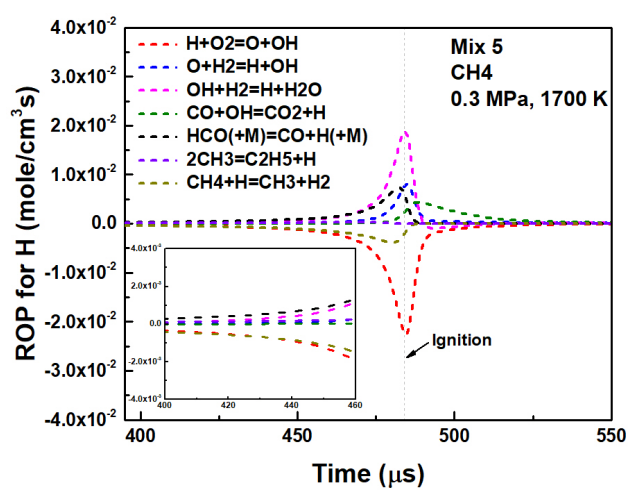

(a) $\mathrm{H}$ production for Mixture 5

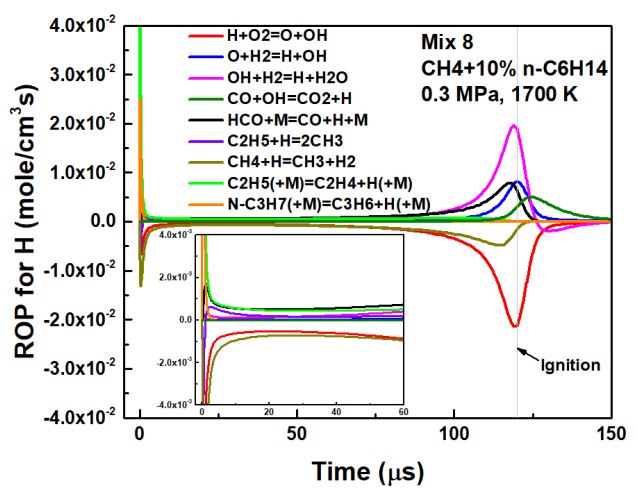

(b) $\mathrm{H}$ production for Mixture 8

Figure 13: Comparison of the key reactions for $\mathrm{H}$ production and consumption during the ignition process between (a) Mixture 5 (methane) and (b) Mixture 8 (methane and 10\% n-hexane) at $P=0.3$ $\mathrm{MPa}$ and $T=1700 \mathrm{~K}$. Calculations were performed with the CaltechMech.

Since the addition of $n$-hexane induces an increase of the peak concentration of $\mathrm{H}$ atom whereas that of $\mathrm{O}$ and $\mathrm{OH}$ decrease, rate of production analyses for $\mathrm{H}$ have been performed as shown in Figure 13. Without n-hexane addition, H radical production is initiated after several hundred microseconds. The main reactions which are responsible for $\mathrm{H}$ production before the chain branching reactions are activated correspond to $\mathrm{HCO}(+\mathrm{M})=\mathrm{H}+\mathrm{CO}(+\mathrm{M})$ and $\mathrm{OH}+\mathrm{H}_{2}=\mathrm{H}+\mathrm{H}_{2} \mathrm{O}$. The species $\mathrm{HCO}$ and $\mathrm{H}_{2}$ originate from the slow oxidation sequence of methane, $\mathrm{CH}_{4} \rightarrow \mathrm{CH}_{3}$ $\rightarrow \mathrm{CH}_{2} \mathrm{O} \rightarrow \mathrm{HCO}$. However, with n-hexane addition, $\mathrm{H}$ radical is produced rapidly at the initial stage through the decomposition reactions $\mathrm{C}_{2} \mathrm{H}_{5}(+\mathrm{M})=\mathrm{C}_{2} \mathrm{H}_{4}+\mathrm{H}$ $(+\mathrm{M})$ and $\mathrm{N}-\mathrm{C}_{3} \mathrm{H}_{7}(+\mathrm{M})=\mathrm{C}_{3} \mathrm{H}_{6}+\mathrm{H}(+\mathrm{M})$. The species $\mathrm{C}_{2} \mathrm{H}_{5}$ and $\mathrm{N}_{-} \mathrm{C}_{3} \mathrm{H}_{7}$ originate 
from the rapid decomposition of n-hexane. This early production of active radicals readily triggers $\mathrm{H}$-abstraction reaction on $\mathrm{CH}_{4}$ and as a consequence accelerates the oxidation sequence mentioned above. This results in a continuous production of $\mathrm{H}$ radicals by $\mathrm{HCO}$ decomposition and eventually triggers the ignition via the typical chain branching mechanism $\mathrm{H}+\mathrm{O}_{2}=\mathrm{O}+\mathrm{OH}$ and $\mathrm{O}+\mathrm{H}_{2}=\mathrm{H}+\mathrm{OH}$. Hence, it can be concluded that reduction of the ignition delay time by n-hexane is largely due to the rapid decomposition of n-hexane at initial stage which produces $\mathrm{H}$ atom.

\section{Conclusion}

In the present study, the ignition characteristics of dual-fuel methane-n-hexaneoxygen-diluent mixtures were experimentally and numerically studied over wide ranges of temperature and pressure using a RCM and a ST.

The RCM results show that the two-stage ignition occurs within the temperature range $700-820 \mathrm{~K}$. In addition, the typical NTC behavior of the total ignition was observed. The increase of n-hexane addition, pressure and equivalence ratio shortened the ignition delay time dramatically. In the ST experiments, the addition of $10 \%$ n-hexane (relative to methane) results in a substantial reduction of ignition delay time under fuel-lean conditions but no further reduction was observed with a larger amount of n-hexane addition (20\%). The increase of equivalence ratio weakens the effect of n-hexane addition on shortening the ignition delay time.

Three detailed chemical kinetic mechanisms were evaluated based on a quantitative analysis. LLNLMech and CaltechMech demonstrate the best agreement with the experimental data obtained in the RCM and ST, respectively. Chemical kinetic analyses showed that under RCM conditions, the low-temperature chemistry of nhexane induces $\mathrm{OH}$ radical formation through the decomposition of $\mathrm{H}_{2} \mathrm{O}_{2}$, which plays a critical role during the ignition process. Under ST conditions, the prompt decomposition of n-hexane results in an early production of active radicals, especially $\mathrm{H}$ radical, which accelerates the ignition through typical chain branching mechanism. The large variations of the ignition delay time with the changes of $n$-hexane addition and equivalence ratio explain the large variation observed previously in the delay and location of the ignition during methane-based mixtures piloted-ignition experiments. 
In order to minimize cycle-to-cycle variation of micro-spray ICE, initial conditions before injection as well as the spray dynamics need to be accurately controlled to limit the local variation of composition in the combustion chamber.

Future work should focus on developing a reduced reaction model which combines the low-temperature LLNLMech and high-temperature CaltechMech mechanisms for integration in realistic numerical simulations of micro-spray ICE for optimizing the design of the injector and the geometry of the combustion chamber. In addition, experimental data for hydrocarbon fuel blends more representative of diesel are needed.

\section{Acknowledgments}

Financial support from the Center for Combustion Energy, and 1000 Young Talents program are highly appreciated. CG is grateful to the Conseil Régional du Centre for sponsoring a student fellowship during her stay at Caltech. UN is grateful to Polish-U.S. Fulbright Commission for sponsoring her stay at Caltech as a Visiting Special Student. 


\section{References}

[1] L. Ma, J. Geng, W. Li, P. Liu, Z. Li, The development of natural gas as an automotive fuel in china, Energy Policy 62 (2013) 531 - 539.

URL

http://www.sciencedirect.com/science/article/pii/ S0301421513005739

[2] T. Korakianitis, A. Namasivayam, R. Crookes, Natural-gas fueled sparkignition (SI) and compression-ignition (CI) engine performance and emissions, Progress in Energy and Combustion Science 37 (1) (2011) 89 - 112.

URL http://www.sciencedirect.com/science/article/pii/ S0360128510000377

[3] A. Yousefi, M. Birouk, B. Lawler, A. Gharehghani, Performance and emissions of a dual-fuel pilot diesel ignition engine operating on various premixed fuels, Energy Conversion and Management 106 (2015) 322 - 336.

URL http://www.sciencedirect.com/science/article/pii/ S0196890415009012

[4] S. Schlatter, B. Schneider, Y. Wright, K. Boulouchos, Experimental study of ignition and combustion characteristics of a diesel pilot spray in a lean premixed methane/air charge using a rapid compression expansion machine, in: SAE 2012 World Congress \& Exhibition, SAE International, 2012.

URL https://doi.org/10.4271/2012-01-0825

[5] H. M. Cho, B.-Q. He, Spark ignition natural gas engines-A review, Energy Conversion and Management 48 (2) (2007) 608 - 618.

URL http://www.sciencedirect.com/science/article/pii/ S0196890406001919

[6] J. Naber, D. Siebers, S. D. Julio, C. Westbrook, Effects of natural gas composition on ignition delay under diesel conditions, Combustion and Flame 99 (2) (1994) $192-200$. 
[7] Y. Zhang, Z. Huang, L. Wei, J. Zhang, C. K. Law, Experimental and modeling study on ignition delays of lean mixtures of methane, hydrogen, oxygen, and argon at elevated pressures, Combustion and Flame 159 (3) (2012) 918 - 931. URL http://www.sciencedirect.com/science/article/pii/ S0010218011002951

[8] M. Y. Selim, Effect of engine parameters and gaseous fuel type on the cyclic variability of dual fuel engines, Fuel 84 (7) (2005) 961 - 971.

URL

http://www.sciencedirect.com/science/article/pii/ S0016236104003679

[9] F. Egolfopoulos, P. Cho, C. Law, Laminar flame speeds of methane-air mixtures under reduced and elevated pressures, Combustion and Flame 76 (3) (1989) $375-391$.

URL http://www.sciencedirect.com/science/article/pii/ 0010218089901193

[10] L. Wei, P. Geng, A review on natural gas/diesel dual fuel combustion, emissions and performance, Fuel Processing Technology 142 (2016) 264 - 278.

URL

http://www.sciencedirect.com/science/article/pii/ S0378382015301715

[11] A. Shah, S. S. Thipse, A. Tyagi, S. D. Rairikar, K. P. Kavthekar, N. V. Marathe, P. Mandloi, Literature review and simulation of dual fuel diesel-CNG engines, in: SAE Technical Paper, The Automotive Research Association of India, 2011. URL https://doi.org/10.4271/2011-26-0001

[12] R. Papagiannakis, D. Hountalas, Combustion and exhaust emission characteristics of a dual fuel compression ignition engine operated with pilot diesel fuel and natural gas, Energy Conversion and Management 45 (18) (2004) 2971 2987.

URL

http://www.sciencedirect.com/science/article/pii/ S0196890404000330 
[13] M. Mbarawa, B. E. Milton, R. T. Casey, Experiments and modelling of natural gas combustion ignited by a pilot diesel fuel spray, International Journal of Thermal Sciences 40 (10) (2001) 927 - 936.

URL

http://www.sciencedirect.com/science/article/pii/ S1290072901012790

[14] X. Huang, F. Yang, M. Ouyang, Performance and emission optimization of pilot ignited natural gas diesel engine with single and dual injection pilot strategies and mbc toolkit, in: SAE Technical Paper, SAE International, 2015.

URL https://doi.org/10.4271/2015-01-1985

[15] P. Federico, D. Sahoo, P. Miles, R. Reitz, Modeling the ignitability of a pilot injection for a diesel primary reference fuel: Impact of injection pressure, ambient temperature and injected mass, SAE International Journal of Fuels and Lubricants 7 (1) (2014) 48-64.

URL http: //www.jstor.org/stable/26273059

[16] J. Liu, F. Yang, H. Wang, M. Ouyang, S. Hao, Effects of pilot fuel quantity on the emissions characteristics of a $\mathrm{CNG}$ /diesel dual fuel engine with optimized pilot injection timing, Applied Energy 110 (2013) 201 - 206.

URL http://www.sciencedirect.com/science/article/pii/ S0306261913002201

[17] G. A. Alla, H. Soliman, O. Badr, M. A. Rabbo, Effect of injection timing on the performance of a dual fuel engine, Energy Conversion and Management 43 (2) (2002) $269-277$.

URL http://www.sciencedirect.com/science/article/pii/ S0196890400001680

[18] J. Zheng, J. Wang, Z. Zhao, D. Wang, Z. Huang, Effect of equivalence ratio on combustion and emissions of a dual-fuel natural gas engine ignited with diesel, Applied Thermal Engineering 146 (2019) 738 - 751.

URL

http://www.sciencedirect.com/science/article/pii/ S1359431118339875 
[19] A. Yousefi, H. Guo, M. Birouk, An experimental and numerical study on diesel injection split of a natural gas/diesel dual-fuel engine at a low engine load, Fuel 212 (2018) $332-346$.

URL

http://www.sciencedirect.com/science/article/pii/ S001623611731298X

[20] J. M. S. Mattson, C. Langness, C. Depcik, An analysis of dual-fuel combustion of diesel with compressed natural gas in a single-cylinder engine, in: SAE Technical Paper, SAE International, 2018.

URL https://doi .org/10.4271/2018-01-0248

[21] S. Weber, R. Stegmann, M. Prager, G. Wachtmeister, The effect of inlet valve timing and engine speed on dual fuel NG-diesel combustion in a large bore engine, SAE International Journal of Engines 11 (2018) 229-246.

URL https://doi.org/10.4271/03-11-02-0015

[22] Z. Wang, Z. Zhao, D. Wang, M. Tan, Y. Han, Z. Liu, H. Dou, Impact of pilot diesel ignition mode on combustion and emissions characteristics of a diesel/natural gas dual fuel heavy-duty engine, Fuel 167 (2016) 248 - 256.

URL http://www.sciencedirect.com/science/article/pii/ S0016236115012338

[23] H. K. Suh, Investigations of multiple injection strategies for the improvement of combustion and exhaust emissions characteristics in a low compression ratio (CR) engine, Applied Energy 88 (12) (2011) 5013 - 5019.

URL http://www.sciencedirect.com/science/article/pii/ S0306261911004387

[24] R. Papagiannakis, D. Hountalas, C. Rakopoulos, Theoretical study of the effects of pilot fuel quantity and its injection timing on the performance and emissions of a dual fuel diesel engine, Energy Conversion and Management 48 (11) (2007) $2951-2961$.

URL http://www.sciencedirect.com/science/article/pii/ S0196890407002129 
[25] A.-H. Kakaee, A. Paykani, M. Ghajar, The influence of fuel composition on the combustion and emission characteristics of natural gas fueled engines, Renewable and Sustainable Energy Reviews 38 (2014) 64 - 78.

URL

http://www.sciencedirect.com/science/article/pii/ S1364032114004055

[26] B. Sahoo, N. Sahoo, U. Saha, Effect of engine parameters and type of gaseous fuel on the performance of dual-fuel gas diesel engines-A critical review, Renewable and Sustainable Energy Reviews 13 (6) (2009) 1151 - 1184.

URL http://www.sciencedirect.com/science/article/pii/ S1364032108001020

[27] C. Mueller, W. Cannella, T. Bruno, B. Bunting, H. Dettman, J. Franz, M. Huber, M. Natarajan, W. Pitz, M. Ratcliff, K. Wright, Methodology for formulating diesel surrogate fuels with accurate compositional, ignition-quality, and volatility characteristics, Energy \& Fuels 26 (6) (2012) 3284-3303.

[28] U. Burke, K. P. Somers, P. O’Toole, C. M. Zinner, N. Marquet, G. Bourque, E. L. Petersen, W. K. Metcalfe, Z. Serinyel, H. J. Curran, An ignition delay and kinetic modeling study of methane, dimethyl ether, and their mixtures at high pressures, Combustion and Flame 162 (2) (2015) 315 - 330.

URL http://www.sciencedirect.com/science/article/pii/ S001021801400251X

[29] J. M. Simmie, Detailed chemical kinetic models for the combustion of hydrocarbon fuels, Progress in Energy and Combustion Science 29 (6) (2003) 599 634 .

URL http://www.sciencedirect.com/science/article/pii/ S0360128503000601

[30] L. Spadaccini, M. Colket, Ignition delay characteristics of methane fuels, Progress in Energy and Combustion Science 20 (5) (1994) 431 - 460.

URL http://www.sciencedirect.com/science/article/pii/ 0360128594900116 
[31] R. Mével, U. Niedzielska, J. Melguizo-Gavilanes, S. Coronel, J. E. Shepherd, Chemical kinetics of n-hexane-air atmospheres in the boundary layer of a moving hot sphere, Combustion Science and Technology 188 (11-12) (2016) $2267-$ 2283.

URL https://doi.org/10.1080/00102202.2016.1211886

[32] K. Zhang, C. Banyon, C. Togbé, P. Dagaut, J. Bugler, H. J. Curran, An experimental and kinetic modeling study of n-hexane oxidation, Combustion and Flame 162 (11) (2015) $4194-4207$.

URL http://www.sciencedirect.com/science/article/pii/ S0010218015002576

[33] R. Mével, K. Chatelain, P. Boettcher, G. Dayma, J. Shepherd, Low temperature oxidation of n-hexane in a flow reactor, Fuel 126 (2014) $282-293$.

URL http://www.sciencedirect.com/science/article/pii/ S0016236114002208

[34] D. Davidson, S. Ranganath, K.-Y. Lam, M. Liaw, Z. Hong, Ignition delay time measurements of normal alkanes and simple oxygenates, Journal of Propulsion and Power 26 (2) (2010) 280-287.

[35] V. Zhukov, V. Sechenov, A. Starikovskii, Ignition delay times in lean n-hexaneair mixture at high pressures, Combustion and Flame 136 (1) (2004) 257 - 259. URL http://www.sciencedirect.com/science/article/pii/ S0010218003002517

[36] J. Liang, Z. Zhang, G. Li, Q. Wan, L. Xu, S. Fan, Experimental and kinetic studies of ignition processes of the methane-n-heptane mixtures, Fuel 235 (2019) $522-529$.

[37] J. Farrell, N. Cernansky, F. Dryer, C. Law, D. Friend, C. Hergart, R. McDavid, A. Patel, C. Mueller, H. Pitsch, Development of an experimental database and kinetic models for surrogate diesel fuels, SAE Technical Paper (2007), \# 200701-0201. 
[38] R. Mevel, F. Rostand, D. Lemarie, L. Breyton, J.E. Shepherd, Oxidation of n-hexane in the vicinity of the auto-ignition temperature, Fuel 236 (2019) 373381.

[39] H. Di, X. He, P. Zhang, Z. Wang, M. S. Wooldridge, C. K. Law, C. Wang, S. Shuai, J. Wang, Effects of buffer gas composition on low temperature ignition of iso-octane and n-heptane, Combustion and Flame 161 (10) (2014) $2531-2538$.

URL

http://www.sciencedirect.com/science/article/pii/ S0010218014001242

[40] K. Chatelain, R. Mével, S. Menon, G. Blanquart, J. Shepherd, Ignition and chemical kinetics of acrolein-oxygen-argon mixtures behind reflected shock waves, Fuel 135 (2014) 498 - 508.

URL http://www.sciencedirect.com/science/article/pii/ S0016236114006449

[41] R. Mével, J. E. Shepherd, Ignition delay-time behind reflected shock waves of small hydrocarbons-nitrous oxide(-oxygen) mixtures, Shock Waves 25 (2015) $217-229$.

[42] R. Mével, K. Chatelain, G. Blanquart, J. Shepherd, An updated reaction model for the high-temperature pyrolysis and oxidation of acetaldehyde, Fuel 217 (2018) 226-239.

[43] A. Lutz, R. Kee, J. Miller, Senkin : a fortran program for predicting homogeneous gas phase chemical kinetics with sensitivity analysis, Tech. Rep. Sand878248, Sandia International Laboratories (1992).

[44] R. Kee, F. Rupley, J. Miller, Chemkin II : A fortran chemical kinetics package for the analysis of gas phase chemical kinetics, Tech. Rep. Sand89-8009B, Sandia International Laboratories (1993).

[45] D. Goodwin, H. Moffat, R. Speth, Cantera: An object-oriented software toolkit 
for chemical kinetics, thermodynamics, and transport processes, http://www . cantera.org, version 2.2.0 (2015).

[46] G. Blanquart, P. Pepiot-Desjardins, H. Pitsch, Chemical mechanism for high temperature combustion of engine relevant fuels with emphasis on soot precursors, Combustion and Flame 156 (3) (2009) 588 - 607.

URL

http://www.sciencedirect.com/science/article/pii/ S0010218008003957

[47] M. Mehl, W. J. Pitz, C. K. Westbrook, H. J. Curran, Kinetic modeling of gasoline surrogate components and mixtures under engine conditions, Proceedings of the Combustion Institute 33 (1) (2011) 193 - 200.

URL

http://www.sciencedirect.com/science/article/pii/ S1540748910000787

[48] W. Ji, P. Zhang, T. He, Z. Wang, L. Tao, X. He, C. Law, Intermediate species measurement during iso-butanol auto-ignition, Combustion and Flame 162 (2015) 3541-3553.

[49] D. Davidson, R. Hanson, Fundamental kinetics database utilizing shock tube measurements. Volume 4. ignition delay time measurements, Tech. rep., Stanford University (2014). 